\title{
Comparison of Standard Methods, MTF, and MF, by the Colilert Rapid test for the Enumeration of Coliform Bacteria in High Salinity Water, Arabian gulf, Doha, Qatar
}

\author{
Magda M. Abed El-Atty EL-Magharaby*
}

\begin{abstract}
Colilert Rapid test was compared with the traditional methods (multiple tube fermentation (MTF) and Membrane filtration (MF)) to enumerate total and fecal coliform in marine water. Colilert method is based on specific indicator nutrients: ONPG and MUG for the target microbes, and chemically suppresses non-coliform bacterial growth. It is more rapid, providing results in as little as $18 \mathrm{~h}$ compared to the $24-96 \mathrm{~h}$ required for traditional methods. The results reported that Colilert method was more sensitive in detecting fecal coliform than the traditional methods (MTF and MF). No significance difference between it and MF in enumeration of total coliform. While, there were significant differences with both MF and MTF in enumeration of fecal coliform. It was more close to MF than MTF. The study recommended MF technique for detecting and enumerating coliform bacteria in marine water due to the high values of false positive results detected by Colilert method.
\end{abstract}

\section{INTRODUCTION}

The coastal water is an important economic and recreational resource that is influenced by human activities.(1) The hygienic quality of water is of utmost importance to society, and efficient bacteriological control of water is essential for implementing a good management of this vital resource.(2) The main criterion for assessing the potential health risk of waters is the density of indicator bacteria. Although indicator bacteria do not necessarily cause illness, they are abundant in human waste where pathogenic organisms, such as pathogenic bacteria, viruses, and parasites are also likely to exist.(3) The typical indicators used include total coliform, fecal coliform, Esherichia coli, and enterococci. ${ }^{(4)}$ Total and fecal coliform were recommended by the US Environmental Protection Agency (EPA) in 1976. ${ }^{(5)}$ Indicator bacteria have historically been measured using either membrane filtration (MF) or multiple tube fermentation (MTF), which both as a rule require 24 to $48 \mathrm{~h}$ for completion(6). The

\footnotetext{
* Environmental Health Department, Environmental Chemistry and Biology, HIPH.
} 
Colilert reagent, based on IDEXX's defined substrate technology, is used for the simultaneous detection and confirmations of total coliforms and E. coli in water. It provides specific indicator nutrients: ONPG (O-Nitrophyenyl-B-D-Galactopyran-oside) and MUG (4-Methylum-belliferyl-B-D Hlucuronide) for the target microbes, and chemically suppresses non-coliform bacterial growth. This reagent system is specifically formulated to achieve optimum sensitivity and specificity in the simultaneous detection and identification of total coliform and E. coli. After 24 hours incubation at $35^{\circ} \mathrm{C}$, if $\boldsymbol{E}$. coli is present, the reagent should show yellow color and fluorescence when exposed to a long-wave (365-366 nm) UV lamp. ${ }^{(7)} \quad$ The allure of the Colilert test is that it is more rapid, providing results in as little as $18 \mathrm{~h}$ compared to the $24-96 \mathrm{~h}$ required for traditional methods. It has the additional advantage of being less expensive (3).Qatar is located half way along the western coast of Arabian Gulf. The total area of Qatar's sea waters are approximately $35,000 \mathrm{sq}$. Km (approximately 15\% of the Gulf). Qatar has an extremely shallow sea with an average depth of $30 \mathrm{~m}$. The high evaporation of the water especially in summer, the very low rainfall, and the little fresh water inflow from the land are the main factors which produce very high sea water salinity. The salinity within Qatar's waters varies mainly between 39 ppt and $41 \mathrm{ppt}$ at the surface. At the bottom, close to the offshore boundaries salinity tends to be 1 - 2 ppt higher than that at the surface. ${ }^{(8)}$ So, two major objectives of the present study: are to compare the Colilert method with the standard MTF and MF in quantification of coliform bacteria, and to assess the efficient one used in high salinity water.

\section{MATERIAL AND METHODS}

Sea water samples, $(n=32)$, were collected randomly from the Doha coastal region. Samples were collected aseptically 
in $250 \mathrm{~m} \ell$ sterile Pyrex glass bottles, IDEXX.doc). ${ }^{(9)}$ The last ten samples were placed on ice and transported immediately performed to intensive tests to recovery of to the laboratory and analyzed within an hour. MTF was carried out by using lactose broth for presumptive test and Brilliant green bile broth for confirmed test to estimate the total coliform density and Eijkman medium at $44.5^{\circ} \mathrm{C}$ to estimate the fecal coliform density. MF total Coliform and fecal coliform analyses with m-Endo Agar LES (Fluka) and mFC Agar (Fluka) media respectively were used to estimate the total coliform and fecal coliform densities. The media used and analytical methods were performed in accordance with the standard procedures outlined in standard methods ${ }^{(6)}$. The estimation of total coliform and $E$. coli by Colilert test was performed in accordance with Standard Operating Procedure for: Escherichia coli and Total Coliform using the IDEXX Quanti-Tray/2000 System with Colilert reagent (4010R01 E. coli coliforms and E. coli.

Recovery of coliforms. Following incubation, the backing material of each Quantitray was disinfected by application of $70 \%$ ethanol with a sterile swab. After the residual ethanol evaporated, sterile pipette tips were used to pierce the backing material of all MUG-positive, ONPGpositive wells; all MUG-positive, ONPGnegative wells; all part florescent, two ONPG-positive wells and MUG-negative per tray. One tray was processed per each water sample. One hundred micro-liters of fluid were withdrawn from each well and added to a separate tube containing $5 \mathrm{ml}$ of Ej broth with a Durham tube and incubated at $44.5^{\circ} \mathrm{C}$. After $24 \mathrm{~h}$, all of the tubes were examined for gas formation. At the same time the Ej tubes were inoculated, fluid from each well was used to inoculate selective-differential media. One drop (approximately $20 \mu \mathrm{l}$ ) of well content was 
streaked for isolation on MacConkey agar and $E M B$ agar. Following incubation at $35.0^{\circ} \mathrm{C}$ for $24 \mathrm{~h}$, colonies were examined for lactose utilization. Selected colonies isolated from each Colilert well were stained with gram stain and cultured on tryptone water and incubated at $35^{\circ} \mathrm{C}$. After 48h, all were examined for indol formation. From the positive MTF fecal coliform tubes, full loop from each was streaked also on MacConkey and EMB agar and then stained and tested for indol formation. Selected one typical blue colony (fecal) from positive $\mathrm{m}-\mathrm{FC}$ agar were stained and cultured on tryptone water and incubated at $35^{\circ} \mathrm{C}$. After $48 \mathrm{~h}$, all were examined for indol formation.

\section{Statistics:}

Descriptive analysis, AOVA test, LSD, and Sensitivity tests were done on the results.

\section{RESULTS AND DISCUSSION}

\section{Total coliform}

Results revealed that $12.5 \%$ from samples undetected of total coliform by MTF and $9 \%$ by MF while no samples undetected for total coliform by the Colilert method. MTF method recorded the highest value of total coliform in $9.4 \%$ of samples, MF method recorded the highest value in $37.5 \%$ of samples , and Colilert method recorded the highest value in $53.1 \%$ of samples.

Two samples (6.25\%) were coliform negative by MTF and MF procedure but coliform positive by the Colilert method. Covert et al.,(10) reported one sample only was coliform negative by MTF and MF procedure but coliform positive by the Colilert method.

For the MTF method, the geometric mean value of total coliform was 1.8 MPN/100 ml with standard error of 0.290 MPN/100 ml. For the MF, the geometric mean value was $2.9 \mathrm{CFU} / 100 \mathrm{ml}$ with standard error of $0.192 \mathrm{CFU} / 100 \mathrm{ml}$.For the Colilert method, the geometric mean value was $3.3 \mathrm{MPN} / 100 \mathrm{ml}$ with standard 
error of $0.133 \mathrm{MPN} / 100 \mathrm{ml}$ as presented in table (1).

A number of environmental factors injure or kill coliform bacteria in seawater.(11) Furthermore, salinity has been shown to be detrimental to the survival of $E$. coli and other coliform bacteria, with aged seawater being more toxic than fresh water.(12) The lower recovery efficiencies of coliform may be due to the inhibition of biochemical reactions producing typical positive results in both MTF and MF assay methods. (13)

Attributed to the MTF, the lower values detected may be due to that the enzyme formic hydrogenlyase (which produces hydrogen gas from formic acid) may be impaired or not induced in environmentally stressed cells. ${ }^{(14)}$ An injury of this nature could explain the absence of gas production in the presumptive portion of the MTF test. This is the reason for giving false negative result and consequently lower count recorded by this method.
Olson(14) stated in his study on seawater, a mean increase of $10.4 \%$ in the total coliform count occurred when incorporate of false negative into the coliform MPN method number. Total coliform results by Colilert about 1.8 and 1.1 higher than MTF and MF methods respectively. Noble et al.,(15) reported total coliform were 1.6 to 1.8 times by Colilert higher than those for MF and MTF.

It was noticed that the highest geometric mean value of total coliform reported by the Colilert method, this may be indicated that this method was more sensitive than the standard methods or it may give false positive result due to the presence of interference of bacteria other than coliform bacteria. Previous study (16) indicated that various plant and algal extracts can significantly interfere with the Colilert system's detection of both coliform and E. coli.

In an earlier study, Palmer et al.,(17) also reported higher total coliform recovery in the marine environment when the original 
Colilert was used. They hypothesized that the Colilert medium did a better job of resuscitating coliforms stressed by exposure to highly saline bay water than does conventional recovery medium.

Table (2), contributed to tota I coliform detection, $87.5 \%$ from samples concordance between Colilert and MTF while $90.6 \%$ samples were concordant between Colilert and MF.

The present study reported only $40 \%$ true positive coliform as shown in figure (1), when co-cultured from positive Colilert (yellow well) on selective media for coliform bacteria (Mac-conkey agar and EMB agar). Based on this finding, the geometric mean value of total coliform decreased to about 1.3 MPN/100 ml.

Edberg et al.,(18) found that $82 \%$ of the isolates from positive Colilert were members of total coliform group while Terry et al.,(10) reported only $73 \%$ members of coliform grouping in drinking water. Carlucci and Parmer ${ }^{(11)}$ reported over $75 \%$ of all isolates from marine sites, indicating the presence of the family Vibironaceae members (non coliform members). Palmer et al.,(17) reported false-positive rates of $19 \%$ for total coliform. Published studies suggest that there are substantial false positives, yielding higher total coliform counts from marine water. ${ }^{(17,20)}$

\section{Fecal coliform}

Colilert rapid method detects $E$.coli directly but the standard methods detect fecal coliform as general and then by biochemical tests the $E$. coli can be detected where $E$. coli is a member of fecal coliform.

Result revealed that as shown in figure (2), the three different methods agree of detecting fecal coliform in $3 \%$ only from samples in which Colilert detected the highest value (200 MPN/100 ml). 6\% from samples detected fecal coliform by both Colilert and MF, figure (2) and table (3), from which $3 \%$ detect the higher value by Colilert (300 MPN/100 ml). The same 
samples percent detected fecal coliform by both MF and MTF as shown in figure (2), while the highest percent of samples (9\%) detected fecal coliform by both Colilert and MTF, figure (2) and table (3), from which $6 \%$ detect the higher value by Colilert (200 MPN/100 ml).

Attributed to the undetected fecal coliform, figure (3) showed that about $44 \%$ from samples undetected fecal coliform by the three methods. The highest percent of undetected, $67 \%$, reported by both MF and MTF. 59\% from samples recorded undetected fecal coliform by both Colilert and MTF while both Colilert and MF undetected fecal coliform in $47 \%$ from samples.

It was noticed that, $25 \%$ from samples detected $E$. coli by Colilert method and undetected fecal coliform by other methods, although $E$. coli is considered as a member of fecal coliform. $12.5 \%$ from samples detected fecal coliform by MF and undetected by others while $3 \%$ only detected fecal coliform by MTF and undetected by others.

Generally, the Colilert method reported the highest geometric mean and standard error values of 0.8 and $0.184 \mathrm{MPN} / 100 \mathrm{ml}$, respectively followed by MTF with geometric mean of $0.3 \mathrm{MPN} / 100 \mathrm{ml}$. The lowest mean value $(0.2 \mathrm{CFU} / 100 \mathrm{ml})$ was recorded by MF method. The MF detected the lowest standard error (0.086) as presented in table (1). Fecal coliform as $E$. coli result by Colilert were 2.7 and 4.0 times higher than those for MTF and MF methods, respectively.

The confirmation of positive E. coli , figure (4), detected by Colilert method by streaking on EMB agar, gram staining, and indol test indicated that $33 \%$ were false positive which were yellow color and fluorescent but indol negative and $5 \%$ was false negative which were yellow color and non-fluorescent but indol positive.

Palmer et al.,(17) reported false-positive rates of $15 \%$ for $E$. coli. They stated that 
not all E. coli are MUG positive-false negatives; not all fluorescent organisms are E. coli- false positives.

The confirmation tests on the positive fecal coliform, gas production at $44.5^{\circ} \mathrm{C}$, by MTF indicated that no $E$. coli was recovered while it was recovered from MF technique (indol +ve and -ve gram stain).

Colilert method produces $12,5 \%$ false negative $E$. coli results as stated by Schets et al.(21) They reported that, Colilert is considered less suitable for direct detection of $E$. coli because of the occurrence of high percentage false negative results due to the inability of a fraction of the $E$. coli population to use the substrate incorporated in Colilert for E. coli detection.

Colilert -24 and Colilert -18 should not be used to test for total coliform and $E$. coli on water-bodies where conductivity exceeds 10,000 uS. $^{(7)}$

Qatar marine water has high conductivity which ranges between 58,000-60,000uS. This can explain the highest percent of false positive total coliform and E. coli reported by this study.

\section{Statistical results:}

ANOVA test detected that the presence of highly significance difference within the three methods tested for enumeration of both total and fecal coliform as presented in table (4). The multiple comparisons (LSD) as presented in table (5), recorded highly significance difference at 0.05 level between Colilert method and traditional MTF method in enumeration of total coliform, while no significance difference was recorded between Colilert and traditional MF method in enumeration of total coliform. This indicated that Colilert method was equivalent to the traditional MF method in enumeration of total coliform.

On the other hand, Colilert method was significantly different with the two traditional methods (MTF \& MF) in enumeration of fecal coliform as represented in table (5).

$$
\text { Palmer et al., }{ }^{(17)} \text { stated that there was }
$$


no difference between the Colilert and MTF for the detection of $E$. coli while for the detection of total coliform, the Colilert gave higher numbers than did the MTF method in their study on coastal water in southern California. They concluded that Colilert method is equivalent to the traditional MTF method for the detection of $E$. coli ,which uncomply with the present study, but not for the detection of total coliform which comply with the present study.

Covert $^{(10)}$ et al., stated a statistically significant difference in the number of positive tubes, with the MTF test resulting in more positive tubes.

Noble et al.,(15) stated a statistically significant difference between MTF and Colilert in detecting total coliform.

Compared with MTF, Colilert method showed values of sensitivity, specificity, and precision of, respectively, 25\%, $90 \%$, and $60 \%$ for detecting more positive fecal coliform. On the other hand, compared with MF, Colilert method showed values of sensitivity, specificity, and precision of, respectively, $16.7 \%, 75 \%$, and $28 \%$ for detecting more positive fecal coliform.

These values indicated that the Colilert method was more closed to the MF than MTF. Colilert 18 is not recommended for the enumeration of total coliforms from marine water. Published studies suggest that there are substantial false positives, yielding higher total coliform counts from marine water. ${ }^{(17,20)}$

\section{CONCLUSSION AND RECOMMENDATIONS}

The study reported that Colilert method was more sensitive in detecting fecal coliform than the traditional methods (MTF and MF). No significance difference was detected between it and MF in enumeration of total coliform. The study recommended the following:

- The Colilert method was not acceptable in high salinity water due to the substantial of high rate of false positive and false negative results.

- The environmental laws must specify 
the method used in enumeration of total and fecal coliform in marine water.

- If Colilert method is used, the limits must be higher than the standard traditional methods (MTF and MF). must becarried out, if colilert method is used.

- The study recommended the use of MF method for the enumeration of coliform in such marine water and for marine water in general.

- High dilution, (1/100), of samples

Table (1): The descriptive analysis of the results obtained by the different methods

\begin{tabular}{|l|l|c|c|c|c|}
\hline & & $\begin{array}{c}\text { Geometric } \\
\text { mean }\end{array}$ & Std. Error & Minimum & Maximum \\
\hline \multirow{4}{*}{ Total coliform } & MTF & 1.8212 & 0.28996 & 0 & 5.04 \\
\cline { 2 - 6 } & Colilert & 3.2923 & 0.1327 & 2.3 & 5.4 \\
\cline { 2 - 6 } & MF & 2.8661 & 0.192 & 0 & 4.15 \\
\cline { 2 - 6 } & Total & 2.6599 & 0.13817 & 0 & 5.4 \\
\hline \multirow{4}{*}{ fecal coliform } & MTF & 0.2502 & 0.11876 & 0 & 2.48 \\
\cline { 2 - 6 } & Colilert & 0.7846 & 0.18369 & 0 & 2.81 \\
\cline { 2 - 6 } & MF & 0.1875 & 0.08616 & 0 & 1.93 \\
\cline { 2 - 6 } & Total & 0.4074 & 0.08226 & 0 & 2.81 \\
\hline
\end{tabular}

Table (2): Concordance between Colilert and MTF and MF in detecting and undetecting total coliform

\begin{tabular}{l|c|c|c|c}
\hline & \multicolumn{2}{|c|}{ MTF } & \multicolumn{2}{c}{$\mathrm{MF}$} \\
\hline & $+\mathrm{Ve}$ & $-\mathrm{Ve}$ & $+\mathrm{Ve}$ & $-\mathrm{Ve}$ \\
\hline Colilert $+\mathrm{Ve}$ & $87.5 \%$ & $12.5 \%$ & $90.4 \%$ & $9.4 \%$ \\
\hline Colilert $-\mathrm{Ve}$ & $0 \%$ & $0 \%$ & $0 \%$ & $0 \%$ \\
\hline
\end{tabular}

Table (3): Concordance between Colilert and MTF and MF in detecting and undetecting fecal coliform

\begin{tabular}{l|c|c|c|c}
\hline & \multicolumn{2}{|c|}{ MTF } & \multicolumn{2}{c}{ MF } \\
\hline & $+\mathrm{Ve}$ & $-\mathrm{Ve}$ & $+\mathrm{Ve}$ & $-\mathrm{Ve}$ \\
\hline Colilert $+\mathrm{Ve}$ & $9.4 \%$ & $25 \%$ & $6.3 \%$ & $31.3 \%$ \\
\hline Colilert $-\mathrm{Ve}$ & $6.3 \%$ & $59.3 \%$ & $15.6 \%$ & $46.8 \%$ \\
\hline
\end{tabular}


Table (4): Analysis of variance ( ANOVA test)

\begin{tabular}{|l|c|c|c|c|}
\hline & & df & F & Sig. \\
\hline \multirow{3}{*}{ Log total coliform count } & Between Groups & 2 & 12.406 & 0.000 \\
\cline { 2 - 5 } & Within Groups & 93 & & \\
\cline { 2 - 5 } & Total & 95 & & \\
\hline \multirow{3}{*}{ Log fecal coliform count } & Between Groups & 2 & 5.844 & 0.004 \\
\cline { 2 - 5 } & Within Groups & 93 & & \\
\cline { 2 - 5 } & Total & 95 & & \\
\hline
\end{tabular}

Table (5): the multiple comparison between the different methods (LSD)

\begin{tabular}{|c|c|c|c|c|c|c|c|}
\hline \multirow{2}{*}{$\begin{array}{l}\text { Dependent } \\
\text { Variable }\end{array}$} & \multirow{2}{*}{$\begin{array}{l}\text { (I) } \\
\text { group }\end{array}$} & \multirow{2}{*}{ (J) group } & \multirow{2}{*}{$\begin{array}{c}\text { Mean } \\
\text { Difference (I-J) }\end{array}$} & \multirow{2}{*}{$\begin{array}{l}\text { Std. } \\
\text { Error }\end{array}$} & \multirow{2}{*}{ Sig. } & \multicolumn{2}{|c|}{$\begin{array}{c}95 \% \text { Confidence } \\
\text { Interval }\end{array}$} \\
\hline & & & & & & $\begin{array}{l}\text { Lower } \\
\text { Bound }\end{array}$ & $\begin{array}{l}\text { Upper } \\
\text { Bound }\end{array}$ \\
\hline \multirow{6}{*}{$\begin{array}{l}\text { Log total } \\
\text { coliform } \\
\text { count }\end{array}$} & \multirow{2}{*}{ MTF } & Colilert & $-1.47114\left(^{*}\right)$ & 0.30392 & 0 & -2.0747 & -0.8676 \\
\hline & & filtration & $-1.04487\left(^{*}\right)$ & 0.30392 & 0.001 & -1.6484 & -0.4413 \\
\hline & \multirow{2}{*}{ Colilert } & confirmed & $1.47114\left(^{*}\right)$ & 0.30392 & 0 & 0.8676 & 2.0747 \\
\hline & & filtration & 0.42627 & 0.30392 & 0.164 & -0.1773 & 1.0298 \\
\hline & \multirow{2}{*}{ MF } & confirmed & $1.04487\left(^{*}\right)$ & 0.30392 & 0.001 & 0.4413 & 1.6484 \\
\hline & & Colilert & -0.42627 & 0.30392 & 0.164 & -1.0298 & 0.1773 \\
\hline \multirow{6}{*}{$\begin{array}{l}\text { Log fecal } \\
\text { coliform } \\
\text { count }\end{array}$} & \multirow{2}{*}{ MTF } & Colilert & $-.53437\left(^{*}\right)$ & 0.19195 & 0.007 & -0.9155 & -0.1532 \\
\hline & & filtration & 0.06273 & 0.19195 & 0.745 & -0.3184 & 0.4439 \\
\hline & \multirow{2}{*}{ Colilert } & confirmed & $.53437\left(^{*}\right)$ & 0.19195 & 0.007 & 0.1532 & 0.9155 \\
\hline & & filtration & $.59711\left(^{*}\right)$ & 0.19195 & 0.002 & 0.2159 & 0.9783 \\
\hline & \multirow{2}{*}{ MF } & confirmed & -0.06273 & 0.19195 & 0.745 & -0.4439 & 0.3184 \\
\hline & & & & 5 & 0 & -0.9783 & -0.2159 \\
\hline
\end{tabular}

* The mean difference is significant at the .05 level.

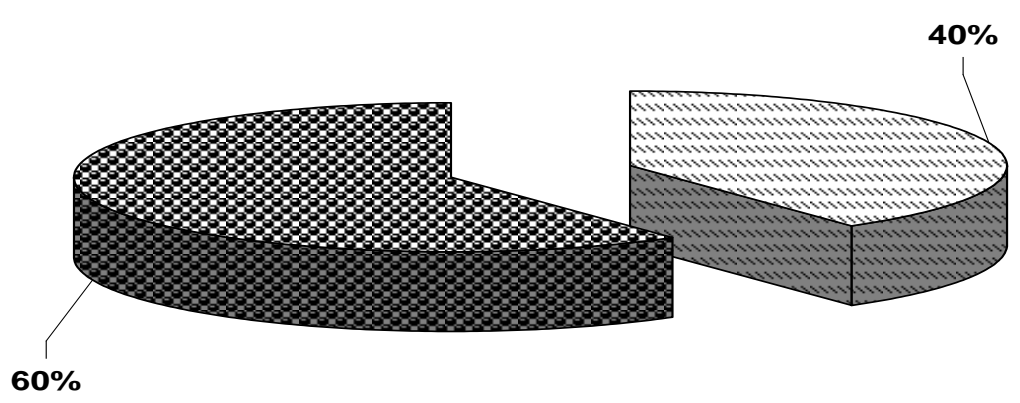

Figute (1): Results of conformatory tests carried out on positive total coliform detected by colilert method 


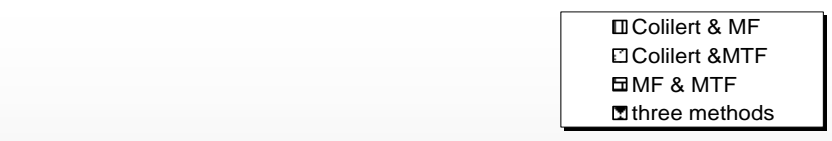

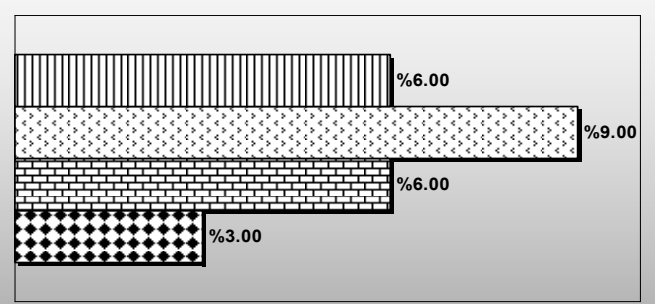

Figure(2): Concordance between the different methods of Detected Fecal Coliform

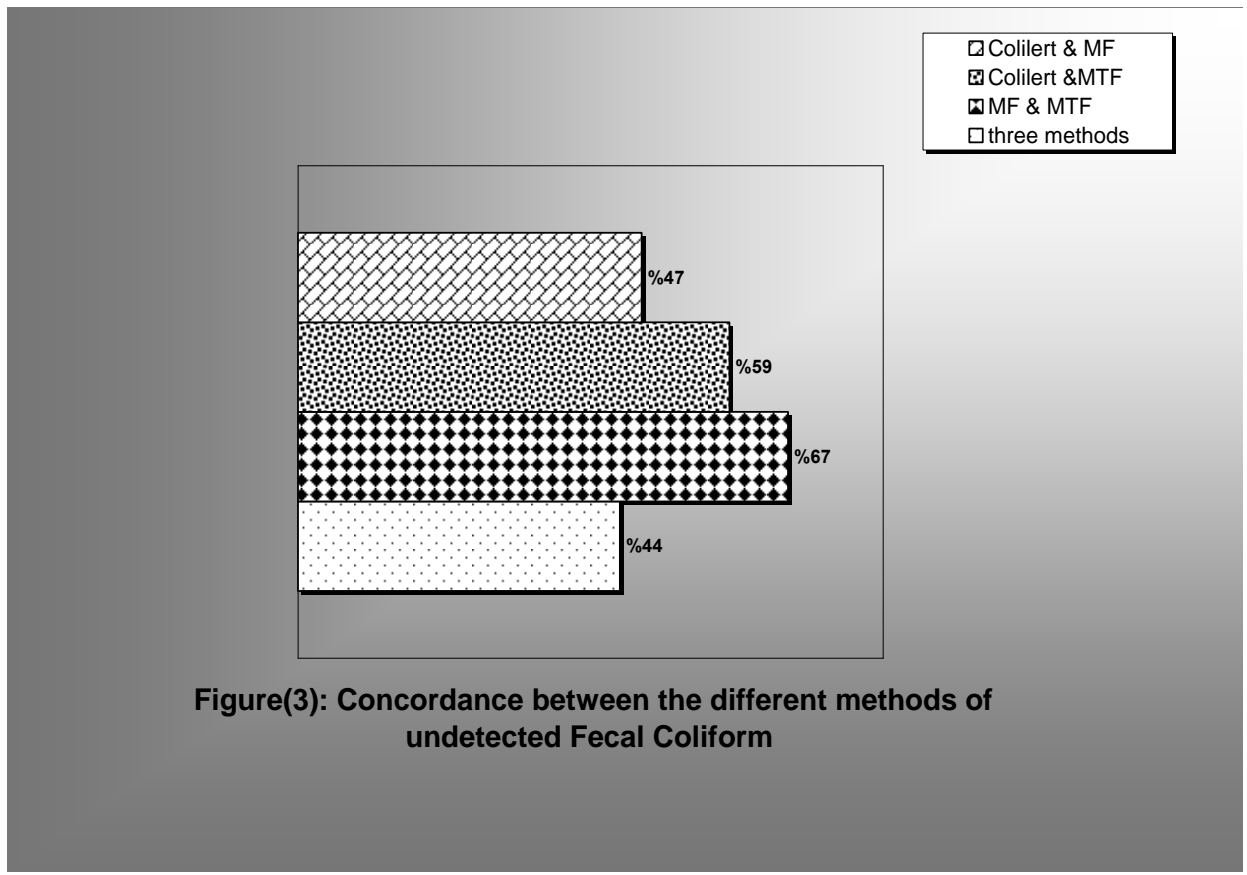




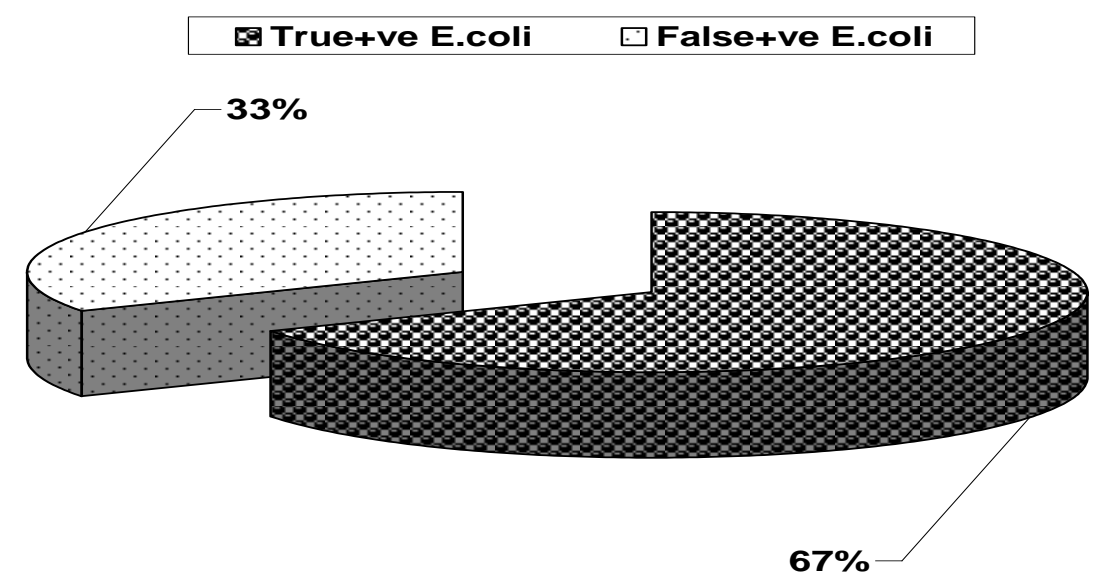

Figure(4): Results of conformatory tests carried out on positive E.coli detected by colilert method

\section{REFERENCES}

1. Schiff KC, Weisberg SB, Raco-Rands VE. Inventory of ocean monitoring in the Southern California Bight. Environ Management. 2002; 871-6.

2. Noble RT, Leecaster MK, McGee CD, Weisberg SB, Ritter K. Comparison of bacterial indicator analysis methods in storm water-affected coastal waters. Water Research. 2004; 38(5): 1183-8.

3. Anglès d'Auriac MB, Roberts $H$, Shaw T, Sirevåg R, Hermansen LF, Berg JD. Field Evaluation of a Semiautomated Method for Rapid and Simple Analysis of Recreational Water Microbiological Quality. Applied and Environmental Microbiology. 2000; 66(10):4401-7.

4. Shibata T, Solo-Gabriele HM, Fleming LE, Elmir S. Monitoring marine recreational water quality using multiple microbial indicators in an urban tropical environment Water Research. 2004;38(30):3119-31.

5. U.S. Environmental Protection Agency. Quality Criteria for Water. EPA440976023. Washington, DC: U.S. Environmental Protection Agency; 1976.

6. Eaton AD, Clesceri S, Greenberg AE Standard methods for the examination of water and wastewater, 19th ed., Washington DC: American Public Health Association (AIHA); 1995.

7. E. coli Colilert $\AA$ Quanti-tray $\AA 2000$ Method Standard Operating Procedure Revised 09/02/04. Available from:www.tecq.state.tx.us/assets/publi c/compliance/monops/crp/QA//Colilert QTrevised090204.doc.

8. Ministry of Municipal Affairs and Agriculture. Available from: 
http://www.mmaa.gov.qa/english/eabo utqatar.htm

9. Missouri State University, Ozarks Environmental and Water. Standard Operating Procedure for: Escherichia coli and Total Coliform using the IDEXX Quanti-Tray/2000 System with Colilert reagent (4010R01 E coli IDEXX.doc) Resources Institute (OEWRI) September 2006. Available from:www.oewri.missouristate.edu/proj ects/SOPs/4010R01\%20Ecoli\%20IDE XX.pdf

10. Covert TC, Shadix IC, Rice EW, Haines JR, Freyberg RW. Evaluation of the Autoanalysis Colilert Test for Detection and Enumeration of Total Coliforms. App. And Env. Micro., 1989; 55(10): 2443-7.

11. Carlucci AF, Factors PF. Affecting the survival of bacteria in sea water. App And Env Micro., 1959; 7: 388-92.

12. Gameson AF, Saxon JG. Field studies on the effect of daylight on mortality of coliform bacteria. Water Res.1967;1: 279-95.

13. Bissonnette GD, Jezeski JJ, McFeters GA, Stuart DG. Evaluation of recovery methods to detect coliforms in water. App And Env Micro. 1977; 33: 590-5.

14. Olson BH. Enhanced accuracy of coliform testing in sea water by a modification of the most probable number method. App And Env Micro. 1978; 36(3): 438-44.

15. Noble RT, Leecaster MK, McGee CD, Weisberg SB, Ritter K. Comparison of bacterial indicators in stormwateraffected coastal waters. Water Res. 2004; 38(5): 1183-8.

16. Davies CM, Apet SC, Peterson SM, Stauber JL. Plant an algal interference in bacterial $\beta$-D- galactosidase and $\beta$ D- glucuronidase assays. App And Env Micro. 1994; 60: 3959-64.

17. Palmer CJ, Tsali Y, Lang AL, Sangermano LR. Evaluation of ColilertMarine Water for Detection of Total Coliforms and Escherichia coli in the Marine Environment. App And Env Micro. 1993; 59(3): 786-90.

18. Edberg SC, Allen MJ, Smith DB. the National Collaborative Study. National field evaluation of a defined substrate method for the simultaneous enumeration of total coliforms and Escherichia coli from drinking waters: comparison with the standard multiple tube fermentation method. App And Env Micro. 1988; 54: 1595-601.

19. Pisciotta JM, Rath DF, Stanek PA, Flanery MD, Harwood VJ. Marine bacteria cause false positive results in the Colilert-18 rapid identification test for Escherichia coli in Florida waters. App And Env Micro. 2002; 68(2): 53944.

20. Eckner KF. Comparison of Membrane Filtration and Multiple-Tube Fermentation by the Colilert and Enterolert Methods for Detection of Waterborne Coliform Bacteria, Escherichia coli and Enterococci Used in Drinking and Bathing Water Quality Monitoring in Southern Sweden. Appl Environ Microbiol. 1998; 64: 3079-83.

21. Schets FM, Noble PJ, Strating S, Mooijman KA, Engels GB, Brouwer A. Comparison of methods for enumeration of total coliforms and Escherichia coli in water samples in the Netherlands. May-2001. Available from: http://hdl.handle.net/10029/9453 